\title{
Influence of Carbon Black/Silica Hybrid Ratio on Properties of Passenger Car Tire Sidewall
}

\author{
Akaporn Limtrakul', Pongdhorn Sae-Oui ${ }^{2}$, Manuchet Nillawong ${ }^{3}$, Chakrit Sirisinha ${ }^{3 *}$ \\ ${ }^{1}$ Department of Chemistry, Faculty of Science, Mahidol University, 10400 Bangkok, 272 Rama 6 Road, Thailand \\ ${ }^{2}$ National Metal and Materials Technology Center (MTEC), National Science and Technology Development Agency, \\ 12120 Khlong Nueng, 114 Thailand Science Park, Phahonyothin Road, Thailand \\ ${ }^{3}$ Rubber Technology Research Centre (RTEC), Faculty of Science, Mahidol University, 73170 Salaya, 4 Phuttamonthon Road, Thailand \\ * Corresponding author, e-mail: chakrit.sir@mahidol.ac.th
}

Received: 22 February 2021, Accepted: 28 May 2021, Published online: 20 October 2021

\begin{abstract}
Influence of carbon black (CB)/precipitated silica $\left(\mathrm{SiO}_{2}\right)$ hybrid ratio on properties of a passenger car tire (PCT) sidewall based on natural rubber (NR) and butadiene rubber (BR) blend was investigated. Rubbers filled with various hybrid filler ratios at a constant loading of $50 \mathrm{phr}$ were prepared and tested. The filler reinforcement efficiency in association with crucial properties of the tire sidewall were of interest. Results show the enhanced rubber-filler interaction with increasing $\mathrm{SiO}_{2}$ fraction leading to the improvement in many vulcanizate properties including hardness, tensile strength, tear strength and fatigue resistance, at the expense of cure efficiency and hysteretic behaviors (i.e., reduced heat build-up resistance and increased dynamic set). The results also suggest the improvement in tire sidewall performance of the NR/BR vulcanizates reinforced with $\mathrm{CB} / \mathrm{SiO}_{2}$ hybrid filler, compared to that of the CB-filled vulcanizate. Keywords
\end{abstract}

hybrid filler, filler reinforcement, tire sidewall, mechanical properties, viscoelastic properties

\section{Introduction}

Reinforcing filler is one of the most critical ingredients in tire production. Typically, tire formulations contain approximately $30 \%$ by weight of reinforcing fillers, mainly carbon black $(\mathrm{CB})$ and precipitated silica $\left(\mathrm{SiO}_{2}\right)$ [1]. Reinforcing fillers not only reduce the product cost, but also improve the overall performance of the tires. Generally, CB can increase resistances to tensile, tear and abrasion at the expense of a drastic increase of energy dissipation and thus the undesirably increased heat build-up of the tires under service conditions. Precipitated $\mathrm{SiO}_{2}$ is also another important reinforcing filler widely used in the rubber industry. Due to the existence of hydroxyl groups on its surface, $\mathrm{SiO}_{2}$ is not compatible with most non-polar rubbers, including natural rubber (NR), styrene-butadiene rubber (SBR) and butadiene rubber (BR). With the advent of a silane coupling agent, the reinforcement of $\mathrm{SiO}_{2}$ has been dramatically improved due to the enhancement of rubber-filler interaction and better filler dispersion [2-8].

Typically, car tire consists of many components, including tread, belt plies, inner liner, beads and sidewall. As tread is the only part of the tire contacting the road surface [9], it is engineered to provide many specific features, including high wear resistance, excellent wet traction and braking ability and low rolling resistance. Extensive research and development has been focused on tire tread compounds to improve tire performance through the application of various hybrid fillers. A partial replacement of CB with silanetreated $\mathrm{SiO}_{2}$ has recently gained much attention from many tire manufacturers. This is because of its many benefits over the sole use of $\mathrm{CB}$ including the greater resistance to chipping and chucking, better wet-grip, lower rolling resistance and reduced heat build-up [10, 11]. Different ratios of $\mathrm{CB} / \mathrm{SiO}_{2}$, in association with the use of silane coupling agent, have been used in the tread production to balance tire wear resistance, rolling resistance and wet grip index, leading to an optimal tire performance $[12,13]$.

Apart from the tire tread, tire sidewall is one of the critical tire components because it helps absorb the shock generated by hitting road bumps and, thus, provides the ride comfort. Also, the sidewall offers lateral stability and protection of the body plies. The most desirable properties of tire sidewall are high resistance to flex cracking and low 
heat build-up $[14,15]$. The sidewall compounds are, therefore, mostly made from NR/BR blends filled with medium-reinforcing CB, particularly N550 [16] or N660 [17]. Surprisingly, disclosure of the compounding technology concerning the property improvement of tire sidewall is still limited. To date, there are published works focusing on the crack-growth resistance improvement of tire sidewall by blending CB-filled NR with BR [18] and on the fatigue resistance enhancement with reduced heat build-up by the use of a reactive multifunctional compatibilizer in CB-filled NR/BR blends [19]. Unlike in the tread applications, little attention has been paid to the use of $\mathrm{CB} / \mathrm{SiO}_{2}$ hybrid filler technology for improving crucial properties of the tire sidewall compounds. Thus, the present work attempted to close the gap by focusing on the application of $\mathrm{CB} / \mathrm{SiO}_{2}$ hybrid filler to improve the properties of the tire sidewall compounds. The reinforcement efficiency provided by various $\mathrm{SiO}_{2} / \mathrm{CB}$ loading ratios was of interest, and the optimal hybrid loading ratio demonstrating the synergistic effect was drawn and discussed.

\section{Experimental}

\subsection{Materials}

\subsubsection{Preparation of the sidewall compounds}

Table 1 discloses the compounding ingredients used in this work. A blend of $60 / 40 \mathrm{NR} / \mathrm{BR}$ was selected to offer an optimum crack growth resistance, as previously reported [20, 21]. While the total amount of hybrid filler was kept constant at $50 \mathrm{phr}$, the weight ratios of $\mathrm{CB}$ to $\mathrm{SiO}_{2}$ were varied as follows: 50/0, 40/10, 30/20, 20/30, 10/40 and $0 / 50$ and designated as $\mathrm{CB} / \mathrm{SiO}_{2} 50 / 0, \mathrm{CB} / \mathrm{SiO}_{2} 40 / 10$, $\mathrm{CB} / \mathrm{SiO}_{2} 30 / 20, \mathrm{CB} / \mathrm{SiO}_{2} 20 / 30, \mathrm{CB} / \mathrm{SiO}_{2} 10 / 40$ and $\mathrm{CB} /$ $\mathrm{SiO}_{2} 0 / 50$, respectively. Details of the compounding recipe are shown in Table 2. Rubber compounds were prepared using an internal mixer (Brabender-Plasticorder 350E, Germany) equipped with tangential rotors. The two-step mixing technique was used as follows. In the first step, the mixer was set at a fill factor of 0.75 , a rotor speed of $40 \mathrm{rpm}$ and a set chamber temperature of $70{ }^{\circ} \mathrm{C}$. After filler incorporation, the rotor speed was raised to $70 \mathrm{rpm}$ during the last $240 \mathrm{~s}$ of the mixing process to increase the batch temperature for accelerating the silanization reaction between coupling agent (TESPT) and silica. The total mixing time was kept constant at $900 \mathrm{~s}$. The compounds were then sheeted on a two-roll mill and cooled down. In the second step, the compounds were mixed with curatives at a set temperature of $50{ }^{\circ} \mathrm{C}$ for $240 \mathrm{~s}$ before being sheeted and kept overnight at room temperature. Details of the mixing sequence are illustrated in Tables 3 and 4.

\subsection{Characterization}

Characterization of the uncured compounds included the measurements of bound rubber content (BRC), Mooney viscosity and cure characteristics. The BRC measurement was performed by extracting the unbound rubber with toluene at room temperature [22, 23]. Approximately $0.2 \mathrm{~g}$ of the uncured sample was cut into small pieces and placed into a metal cage. The sample was then immersed in $25 \mathrm{~mL}$ of toluene at room temperature for $168 \mathrm{hrs}$, and the solvent was renewed every 3 days. The sample was subsequently filtered, dried at room temperature for one day, and then at $75^{\circ} \mathrm{C}$ until a constant weight was gained. The calculation of BRC is expressed in Eq. (1) [22-27]. Although the Eq. (1) is intentionally established for rubber filled with only filler(s), it is practically applicable for conventional compounds containing other ingredients such as sulfur, accelerators, and anti-degradants because these chemicals are soluble in toluene and, thus, do not interfere with the accuracy of the BRC measurement.

$$
\operatorname{BRC}(\%)=\frac{W_{\mathrm{fg}}-W\left[m_{\mathrm{f}} /\left(m_{\mathrm{f}}+m_{\mathrm{p}}\right)\right]}{W\left[m_{\mathrm{f}} /\left(m_{\mathrm{f}}+m_{\mathrm{p}}\right)\right]} \times 100,
$$

where $W_{\mathrm{fg}}$ is the weight of fillers and gel, $m_{\mathrm{f}}$ is the weight of the fillers in the compound, $m_{\mathrm{p}}$ is the weight of the polymer in the compound, and $W$ is the weight of the specimen.

Mooney viscosity (ML $\left.(1+4) @ 100{ }^{\circ} \mathrm{C}\right)$ was measured using a Mooney viscometer (GOTECH model MV-3000U, Taiwan) according to ISO 289-1:2015 [28]. Cure behavior was monitored using a moving die rheometer (MDR, TechPro MD+, USA) at $160{ }^{\circ} \mathrm{C}$ following ISO 6502$3: 2018$ (en) [29]. Also, the cure test under $100 \%$ strain was conducted to impede the formation of the filler-filler network during the cure test by the use of Rubber Process Analyzer (Alpha Technologies model RPA2000, USA). Payne effect was determined by using the RPA2000 at a frequency of $1.7 \mathrm{~Hz}$ and temperature of $100{ }^{\circ} \mathrm{C}$. A strain sweep test was carried out, and the difference of storage shear moduli $\left(\Delta G^{\prime}\right)$ at $0.56 \%$ and $100.0 \%$ was selected to represent the Payne effect magnitude. After the cure test, the vulcanized samples were prepared using a compression molding technique at $160{ }^{\circ} \mathrm{C}$ for the optimum cure time $\left(t_{c}^{\prime}(95)\right)$ as predetermined from the MDR cure curve.

After vulcanization, a swelling test was performed by soaking the weighed test pieces with a dimension of approximately $1 \times 1 \times 0.2 \mathrm{~cm}^{3}$ in toluene at room temperature for $120 \mathrm{hrs}$. Thereafter, the swollen test pieces were taken out, blotted gently by filter paper and weighed $\left(\mathrm{W}_{2}\right)$. The test pieces were then dried in an oven at $70{ }^{\circ} \mathrm{C}$ until a 
Table 1 List of materials used in the present study

\begin{tabular}{|c|c|}
\hline Ingredients & Suppliers \\
\hline Natural rubber (STR 5L, $\left.88 \mathrm{ML}(1+4) @ 100{ }^{\circ} \mathrm{C}\right)$ & Union Rubber Product Co., Ltd., Thailand \\
\hline $\begin{array}{l}\text { Butadiene rubber (BR- } 150 \text { with } 43 \mathrm{ML}(1+4) @ 100^{\circ} \mathrm{C}, 98 \mathrm{wt} \% \text { of } \\
\text { cis content, } 1 \mathrm{wt} \% \text { of trans content, and } 1 \mathrm{wt} \% \text { of vinyl content) }\end{array}$ & UBE Industries, Ltd., Japan \\
\hline N-isopropyl-N'-phenyl-p-phenylene diamine (IPPD) & Monflex Pte. Ltd., Singapore \\
\hline 2,2,4-trimethyl-1,2-dihydroquinoline (TMQ) & Monflex Pte. Ltd., Singapore \\
\hline N-tert-butyl-2-benzothiazole sulfenamide (TBBS) & Monflex Pte. Ltd., Singapore \\
\hline Bis (triethoxysilylpropyl) tetrasulfide (TESPT) & Innova (Tianjin) Chemical Co., Ltd., China \\
\hline Carbon black (N660) with BET specific surface area of $35 \pm 5 \mathrm{~m}^{2} / \mathrm{g}$ & Thai Carbon Black Public Co., Ltd., Thailand \\
\hline Silica (Tokusil 255) with BET specific surface area of $166 \mathrm{~m}^{2} / \mathrm{g}$ & OSC Siam Silica Co., Ltd., Thailand \\
\hline Naphthenic oil & PSP Specialties Co., Ltd., Thailand \\
\hline Microcrystalline wax & Petch Thai Chemical Co., Ltd., Thailand \\
\hline Stearic acid & Kij Paiboon Chemical Ltd., Part., Thailand \\
\hline Zinc oxide $(\mathrm{ZnO})$ & Thai-Lysaght Co., Ltd., Thailand \\
\hline Sulfur & Siam Chemicals Public Co., Ltd., Thailand \\
\hline
\end{tabular}

Table 2 Compounding recipes

\begin{tabular}{lcccccc}
\hline \multirow{2}{*}{ Ingredients } & \multicolumn{5}{c}{$\mathrm{CB} / \mathrm{SiO}_{2}$ Loading (phr/phr) } \\
\cline { 2 - 7 } NR & $50 / 0$ & $40 / 10$ & $30 / 20$ & $20 / 30$ & $10 / 40$ & $0 / 50$ \\
BR-150 & 60.0 & 60.0 & 60.0 & 60.0 & 60.0 & 60.0 \\
ZnO & 40.0 & 40.0 & 40.0 & 40.0 & 40.0 & 40.0 \\
Stearic acid & 4.0 & 4.0 & 4.0 & 4.0 & 4.0 & 4.0 \\
Microcrystalline wax & 1.5 & 1.5 & 1.5 & 1.5 & 1.5 & 1.5 \\
Naphthenic oil & 3.0 & 3.0 & 3.0 & 3.0 & 3.0 & 3.0 \\
Carbon black (N660) & 4.0 & 4.0 & 4.0 & 4.0 & 4.0 & 4.0 \\
Silica (Hisil 255) & 50.0 & 40.0 & 30.0 & 20.0 & 10.0 & 0.0 \\
TESPT (10\% w/w of $\mathrm{SiO}_{2}$ ) & 0.0 & 10.0 & 20.0 & 30.0 & 40.0 & 50.0 \\
IPPD & 0.0 & 1.0 & 2.0 & 3.0 & 4.0 & 5.0 \\
TMQ & 1.5 & 1.5 & 1.5 & 1.5 & 1.5 & 1.5 \\
TBBS & 1.0 & 1.0 & 1.0 & 1.0 & 1.0 & 1.0 \\
Sulfur & 1.0 & 1.0 & 1.0 & 1.0 & 1.0 & 1.0 \\
\hline
\end{tabular}


Table 3 Mixing sequence used in this study; $\mathbf{1}^{\text {st }}$ mixing step: Fill factor: 0.75 ; set temperature: $70{ }^{\circ} \mathrm{C}$, rotor speed: $40 \mathrm{rpm}(0-660 \mathrm{~s})$ and

\begin{tabular}{lc}
\multicolumn{2}{c}{$70 \mathrm{rpm}(661-900 \mathrm{~s})$} \\
\hline Time $(\mathrm{s})$ & Ingredients added \\
\hline 0 & $\mathrm{NR}+\mathrm{BR}$ \\
& $1 . \mathrm{ZnO}+$ stearic acid and microcrystalline wax \\
120 & $2.1 / 2 \mathrm{CB}+1 / 2 \mathrm{SiO}_{2}+1 / 2 \mathrm{TESPT}+$ naphthenic oil \\
& $3.1 / 2 \mathrm{CB}+1 / 2 \mathrm{SiO}_{2}+1 / 2 \mathrm{TESPT}$ \\
660 & $\mathrm{IPPD}+\mathrm{TMQ}$ \\
900 & Discharge \\
\hline
\end{tabular}

Table 4 Mixing sequence used in this study;

$2^{\text {nd }}$ mixing step: Rotor speed: $40 \mathrm{rpm}$; set temperature: $50{ }^{\circ} \mathrm{C}$

\begin{tabular}{lc}
\hline Time (s) & Ingredient added \\
\hline 0 & NR/BR mix \\
60 & TBBS and sulfur \\
240 & Discharge \\
\hline
\end{tabular}

constant weight was obtained $\left(\mathrm{W}_{1}\right)$. Swelling ratio $(\mathrm{S})$ was calculated by Eq. (2):

$\mathrm{S}(\%)=\left(\mathrm{W}_{2} / \mathrm{W}_{1}\right) \times 100$.

Hardness test was performed according to ISO 48-4:2018 [30] using a durometer (Wallace Shore A, UK). At least five measurements were carried out for each sample at different locations. Elastic modulus $\left(G^{\prime}\right)$ at $1.95 \%$ strain of the vulcanizate was measured using the RPA2000 at a frequency of $1.7 \mathrm{~Hz}$ and a temperature of $100{ }^{\circ} \mathrm{C}$.

Tensile properties (i.e., tensile strength, stress at $100 \%$ elongation or $100 \%$ modulus (M100), elongation at break) and tear strength were measured using a universal testing machine (Instron 3366 series, USA) as per ISO 37:2017(en) [31] (die type 1) and ISO 34-1:2010 [32] (method B), respectively. Determination of heat build-up (HBU) was carried out in accordance with ISO 4666-3:2010 [33] by using a Goodrich flexometer (BF Goodrich Model II, USA). The temperature increases at the specimen's base were recorded. Values of the dynamic set were also reported together with the heat build-up results. Fatigue resistance was determined according to ISO 132:2017 [34] using a De Mattia flexing machine (GOTECH model GT-7011-D, Taiwan).

\section{Results and discussion}

Fig. 1 demonstrates bound rubber content (BRC) results of the compounds filled with various $\mathrm{CB} / \mathrm{SiO}_{2}$ hybrid ratios. As expected, the $\mathrm{SiO}_{2}$-filled system (i.e., $\mathrm{CB} / \mathrm{SiO}_{2}=0 / 50$ ) possesses the highest $\mathrm{BRC}$, whereas the CB-filled

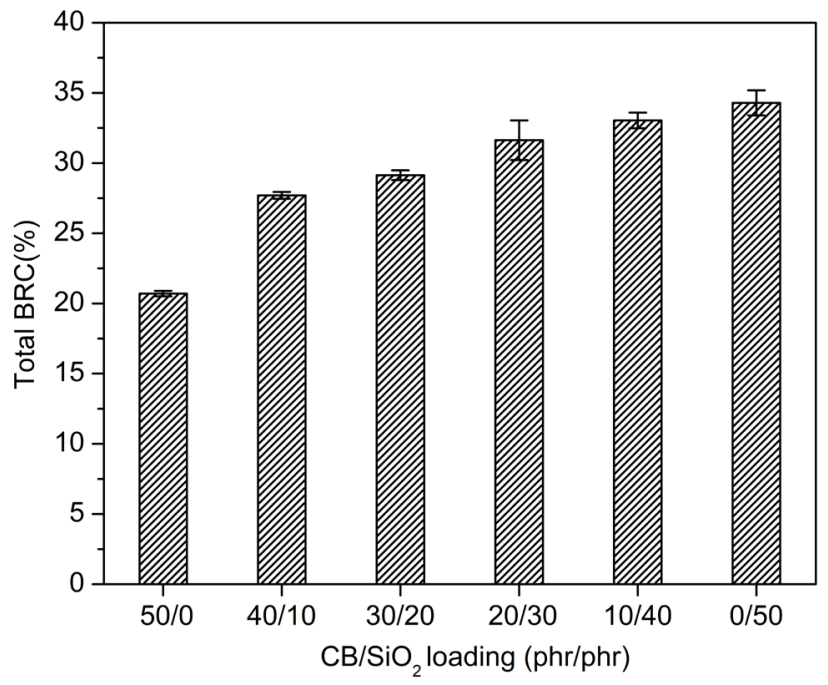

Fig. 1 Bound rubber content of the compounds filled with various $\mathrm{CB} / \mathrm{SiO}_{2}$ hybrid loadings

system $\left(\mathrm{CB} / \mathrm{SiO}_{2}=50 / 0\right)$ shows the lowest BRC. The result is not uncommon because $\mathrm{SiO}_{2}$ used in this work possesses a much greater specific surface area than CB (BET specific surface area: 166 vs. $35 \mathrm{~m}^{2} / \mathrm{g}$ ) meaning that there is much higher contacting surface area and, thus, rubber-filler interaction in the $\mathrm{SiO}_{2}$-filled system. In the case of hybrid filler systems, as one can expect, the BRC increases continuously with increasing $\mathrm{SiO}_{2}$ fraction due to a dilution effect.

Fig. 2 depicts the Payne effect magnitude of the compounds. The Payne effect or filler-filler interaction tends to increase with increasing $\mathrm{SiO}_{2}$ fraction. The result trend is in line with that of the $\mathrm{BRC}$ results, as mentioned earlier. Again, the explanation is given by the considerably higher specific surface area of $\mathrm{SiO}_{2}$, compared to $\mathrm{CB}$, which leads

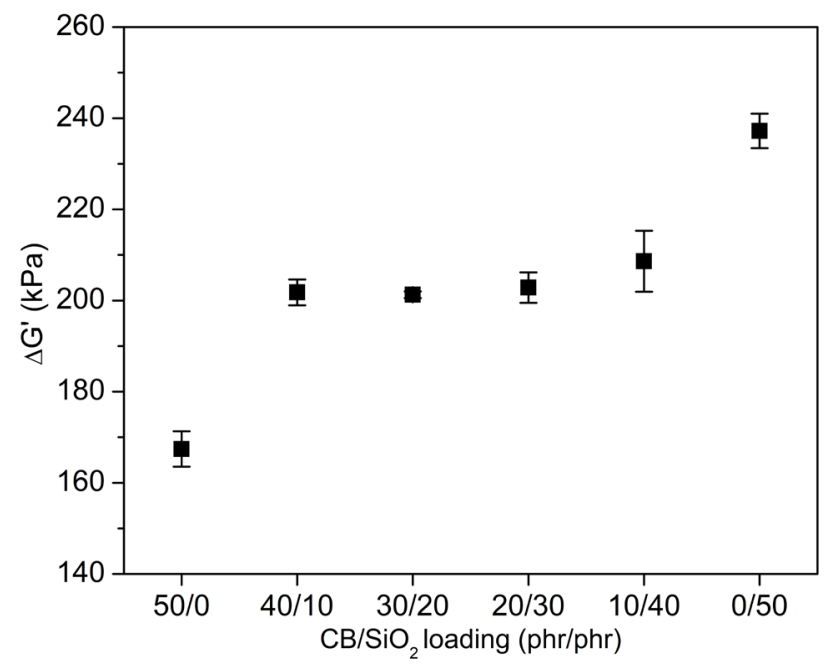

Fig. 2 Payne effect of the compounds filled with various $\mathrm{CB} / \mathrm{SiO}_{2}$ hybrid loadings 
to the increase in rubber-filler interaction (as evidenced from the $\mathrm{BRC}$ results) and the enhanced filler-filler interaction.

Mooney viscosity results of the compounds are illustrated in Fig. 3. As CB (N660) used in this work has a relatively low specific surface area $\left(35 \mathrm{~m}^{2} / \mathrm{g}\right)$ compared to $\mathrm{SiO}_{2}\left(166 \mathrm{~m}^{2} / \mathrm{g}\right)$, the $\mathrm{SiO}_{2}$-filled compound shows much higher viscosity than the CB-filled compound. Surprisingly, in the hybrid filler systems, the viscosity values of the compounds are approximately the same and do not follow the mixture rule. This might be explained by the difference in the degree of filler dispersion. In the CB-rich filled systems, shearing force during mixing was relatively low due to the low specific surface area of $\mathrm{CB}$, resulting in a relatively poor $\mathrm{SiO}_{2}$ dispersion when compared to the $\mathrm{SiO}_{2}$-rich systems. Viscosity values of the CB-rich filled system are therefore unexpectedly high. It is also noticeable that the Mooney viscosity results are analogous to the Payne effect results (see Fig. 2).

Cure curves of the compounds are shown in Fig. 4 and the extracted data are summarized in Table 5. Both $t_{s 2}$ and $t_{c}^{\prime}(95)$ tend to increase with increasing $\mathrm{SiO}_{2}$ fraction. A similar observation is reported elsewhere $[35,36]$ as explained by the cure retardation effect. It is widely accepted that the hydroxyl groups on the $\mathrm{SiO}_{2}$ surface, particularly the ones that do not react with TESPT, can adsorb zinc complex and curatives from the matrix. Interestingly, both $t_{s 2}$ and $t_{c}^{\prime}(95)$ measured from MDR at low strain (ca. $7 \%$ ) are longer than those measured from RPA at high strain (100\%). Such difference could be explained as follows. At low strain (in MDR), there is a slow torque rise as a function of time or the so-called marching phenomenon, which is more pronounced in the $\mathrm{SiO}_{2}$-rich systems. Such phenomenon is, to some

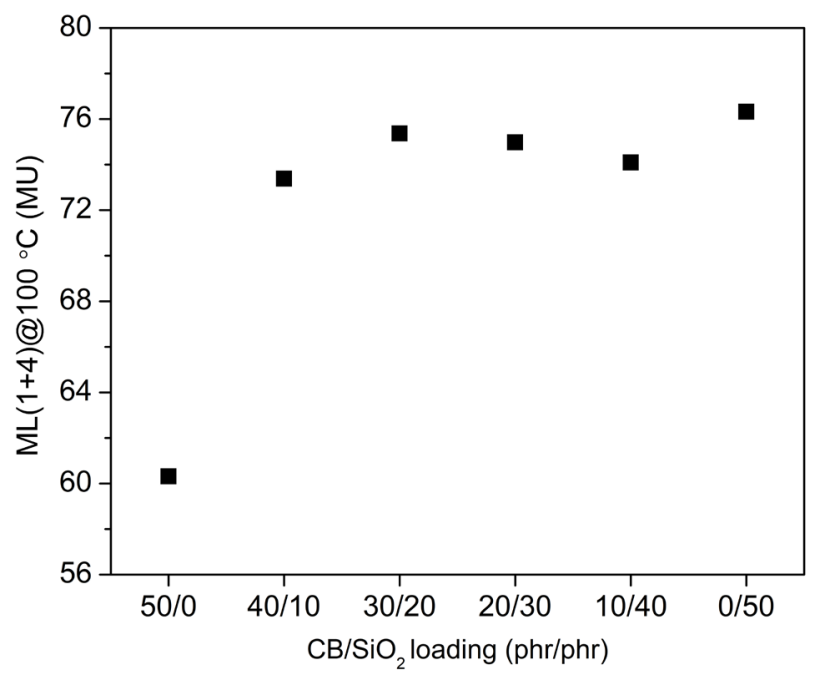

Fig. 3 Mooney viscosity of the compounds filled with various $\mathrm{CB} / \mathrm{SiO}_{2}$ hybrid loadings
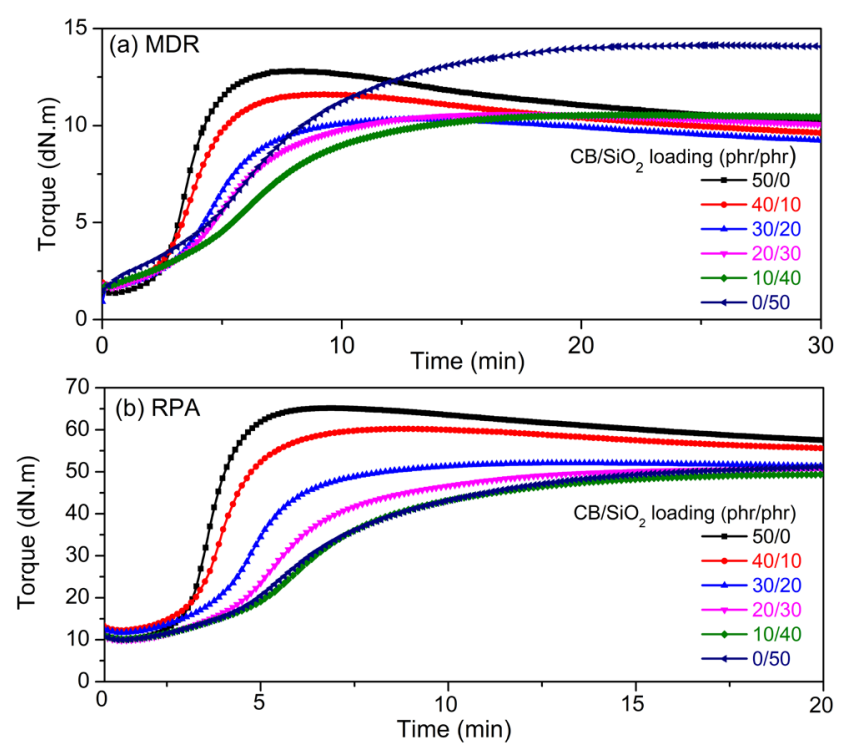

Fig. 4 Cure characteristics of the compounds as measured by (a) MDR at low strain (7\% strain) and (b) RPA at high strain (100\% strain)

extent, caused mainly by the $\mathrm{SiO}_{2}$ transient network formation via the highly reactive silanol groups on the $\mathrm{SiO}_{2}$ surface. Since the $\mathrm{SiO}_{2}$ network formation is a time-consuming process and, thus, causes a delay of maximum torque $\left(\mathrm{M}_{\mathrm{H}}\right)$, $t_{c}^{\prime}(95)$ is therefore prolonged in this case. On the contrary, at a relatively high strain of the RPA test (i.e., $100 \%$ ), the $\mathrm{SiO}_{2}$ network formation is impeded [37-39], and therefore no delay of $t_{c}^{\prime}(95)$ is observed.

Generally, the torque difference $\left(\mathrm{M}_{\mathrm{H}}-\mathrm{M}_{\mathrm{L}}\right)$ is directly proportional to crosslink density. One might expect the lower torque difference values found in the $\mathrm{SiO}_{2}$-filled vulcanizates due to the cure retardation phenomenon as previously mentioned $[2,40,41]$. Unexpectedly, the torque difference value of the $\mathrm{SiO}_{2}$-filled system measured from MDR is comparable to that of the CB-filled one, as illustrated in Table 5. This unexpected finding is caused by the unusual increase in $\mathrm{M}_{\mathrm{H}}$ value of the $\mathrm{SiO}_{2}$-filled vulcanizate resulting from the formation of $\mathrm{SiO}_{2}$ transient network, apart from the chemical crosslinks developed in the rubber matrix. In contrast, by performing the cure test using RPA, the torque interference by the transient filler network is eliminated. The torque difference values become in the proper order, i.e., they decrease with increasing $\mathrm{SiO}_{2}$ fraction, which is in good accordance with the cure retardation phenomenon via the curative adsorption on the $\mathrm{SiO}_{2}$ surface as discussed earlier.

Fig. 5 displays the swelling ratio of the vulcanizates filled with the hybrid filler. As tightly bound rubber is more restricted to swelling by solvent, theoretically, the vulcanizate having higher BRC should have a lower swelling ratio, 
Table 5 Cure characteristics of the compounds as determined from MDR and RPA

\begin{tabular}{lcccccccc}
\hline \multirow{2}{*}{$\begin{array}{l}\mathrm{CB} / \mathrm{SiO}_{2} \\
\text { Loading }(\mathrm{phr} / \mathrm{phr})\end{array}$} & \multicolumn{2}{c}{$\mathrm{M}_{\mathrm{H}}(\mathrm{dN} \cdot \mathrm{m})$} & \multicolumn{2}{c}{$\mathrm{M}_{\mathrm{H}}-\mathrm{M}_{\mathrm{L}}(\mathrm{dN} \cdot \mathrm{m})$} & \multicolumn{2}{c}{$t_{s 2}(\mathrm{~min})$} & \multicolumn{2}{c}{$t_{c}^{\prime}(95)(\mathrm{min})$} \\
\cline { 2 - 9 } & $\mathrm{MDR}$ & $\mathrm{RPA}$ & $\mathrm{MDR}$ & $\mathrm{RPA}$ & MDR & $\mathrm{RPA}$ & $\mathrm{MDR}$ & $\mathrm{RPA}$ \\
\hline $50 / 0$ & $12.72 \pm 0.13$ & $65.13 \pm 0.04$ & $11.35 \pm 0.13$ & $55.01 \pm 0.08$ & $2.77 \pm 0.02$ & $1.49 \pm 0.01$ & $5.43 \pm 0.07$ & $3.44 \pm 0.04$ \\
$40 / 10$ & $11.46 \pm 0.21$ & $60.16 \pm 0.07$ & $9.75 \pm 0.16$ & $48.05 \pm 0.08$ & $2.94 \pm 0.04$ & $1.50 \pm 0.01$ & $6.36 \pm 0.09$ & $3.57 \pm 0.07$ \\
$30 / 20$ & $10.28 \pm 0.08$ & $52.09 \pm 0.01$ & $8.57 \pm 0.10$ & $40.44 \pm 0.01$ & $3.52 \pm 0.01$ & $1.59 \pm 0.02$ & $9.11 \pm 0.44$ & $4.51 \pm 0.01$ \\
$20 / 30$ & $10.72 \pm 0.18$ & $50.63 \pm 0.03$ & $9.01 \pm 0.08$ & $40.82 \pm 0.10$ & $3.64 \pm 0.05$ & $2.03 \pm 0.02$ & $11.22 \pm 0.10$ & $6.29 \pm 0.03$ \\
$10 / 40$ & $10.68 \pm 0.18$ & $49.43 \pm 0.03$ & $8.89 \pm 0.11$ & $39.40 \pm 0.22$ & $4.00 \pm 0.08$ & $2.11 \pm 0.01$ & $14.11 \pm 0.05$ & $7.40 \pm 0.03$ \\
$0 / 50$ & $14.11 \pm 0.06$ & $51.62 \pm 0.04$ & $11.46 \pm 0.19$ & $41.29 \pm 0.44$ & $4.04 \pm 0.04$ & $2.11 \pm 0.03$ & $16.29 \pm 0.80$ & $8.17 \pm 0.04$ \\
\hline
\end{tabular}

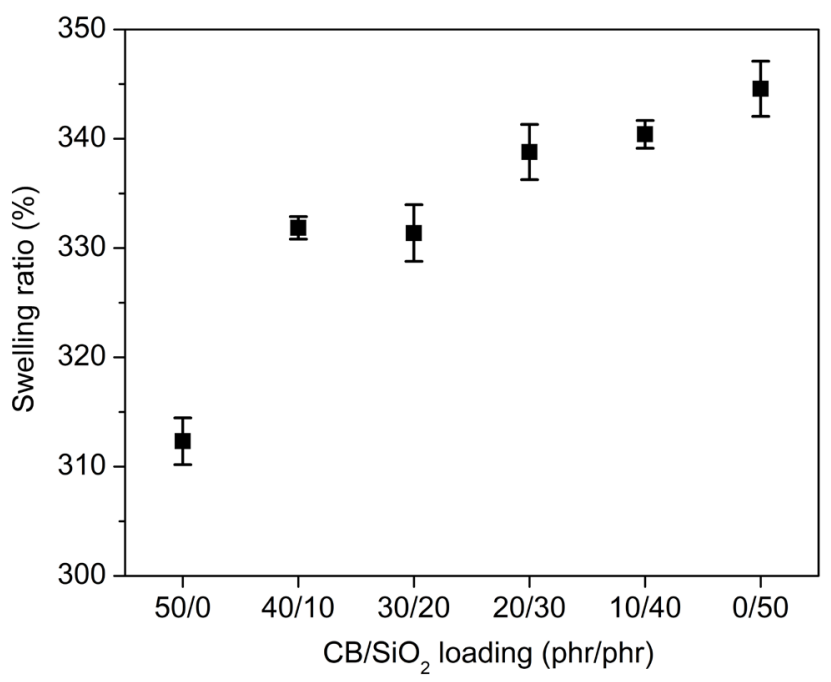

Fig. 5 Swelling ratio of the vulcanizates filled with various $\mathrm{CB} / \mathrm{SiO}_{2}$ hybrid loadings

when compared at a given crosslink density. However, in this work, the highest swelling ratio is found in the $\mathrm{SiO}_{2}$ filled system despite its highest BRC. The lowest crosslink density as evidenced from the torque difference results obtained from RPA might be a possible reason for the finding. Likewise, the lowest swelling ratio of the CB-filled system, despite its lowest BRC, can be explained by the its highest crosslink density. In addition, the cage effect of the grape-like structure of CB might be another reason to restrict the swelling of rubber molecules trapped within the $\mathrm{CB}$ structure. With increasing $\mathrm{SiO}_{2}$ fraction, the rubber vulcanizates exhibit a continuous increase in swelling ratio due possibly to the dilution effect.

Hardness is a measure of the resistance of rubber against surface deformation [42]. Fig. 6 shows the hardness results of the rubber vulcanizates filled with different $\mathrm{CB} / \mathrm{SiO}_{2}$ hybrid fractions. The hardness increases continuously with increasing $\mathrm{SiO}_{2}$ fraction despite the reduced crosslink density. The results imply that the higher rubber-filler interaction (BRC) and the stronger filler-filler network in the $\mathrm{SiO}_{2}$-rich systems play a greater role in the hardness of rubber vulcanizates than the crosslink density. As it is widely known that hardness is closely related to modulus at low strain, shear modulus $\left(G^{\prime}\right)$ at $1.95 \%$ strain of the vulcanizates follows the same trend as the hardness results (see also Fig. 6).

Table 6 illustrates the tensile and tear properties of the rubber vulcanizates. With increasing $\mathrm{SiO}_{2}$ fraction, the improvements in tensile strength and $100 \%$ modulus (M100) are revealed, indicating the greater magnitude of filler reinforcement which could be explained by the enhanced rubber-filler interaction due to the increase of the total contacting surface area of fillers in the vulcanizates. Notably, despite the increased magnitude of filler reinforcement effect, deformability of the vulcanizates represented by the elongation at break value is unexpectedly increased. Such an increase could be explained by the reduced crosslink density, as discussed previously. For the tear test, the result trend is in a similar manner to the tensile test but with a stronger magnitude of enhancement. The substantial improvement in tear strength is caused by the combination of:

1. the filler reinforcement as evidenced by BRC results (see Fig. 1) and

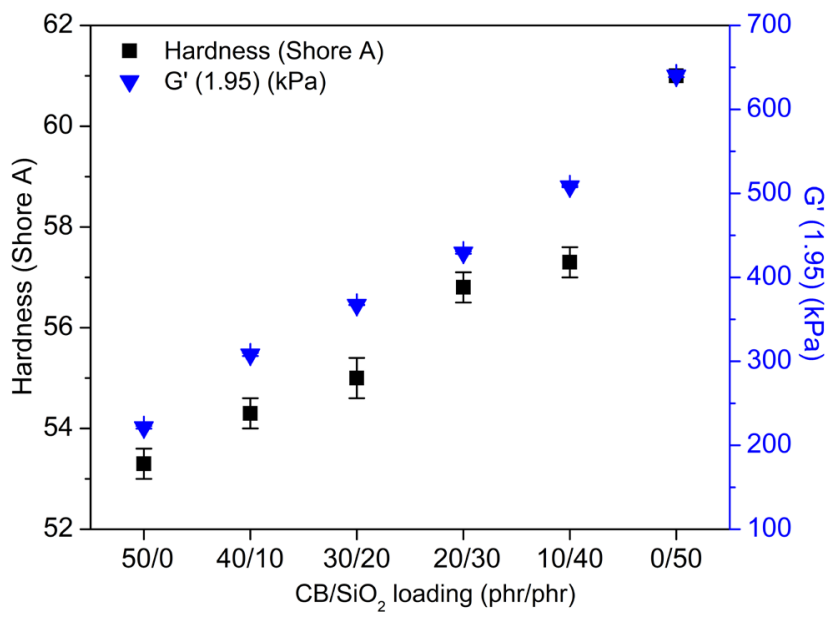

Fig. 6 Hardness and storage modulus $\left(G^{\prime}\right)$ of the vulcanizates filled with various $\mathrm{CB} / \mathrm{SiO}_{2}$ hybrid loadings 
Table 6 Tensile properties and tear strength of the vulcanizates filled with various $\mathrm{CB} / \mathrm{SiO}_{2}$ hybrid loadings

\begin{tabular}{ccccc}
\hline $\begin{array}{c}\mathrm{CB} / \mathrm{SiO}_{2} \\
\text { Loading (phr/phr) }\end{array}$ & Tensile strength (MPa) & Elongation at break (\%) & M100 (MPa) & Tear strength (N/mm) \\
\hline $50 / 0$ & $18.4 \pm 1.3$ & $511 \pm 29$ & $2.09 \pm 0.08$ & $21.9 \pm 1.7$ \\
$40 / 10$ & $20.1 \pm 1.0$ & $550 \pm 31$ & $1.92 \pm 0.10$ & $46.1 \pm 4.0$ \\
$30 / 20$ & $20.6 \pm 0.4$ & $600 \pm 41$ & $2.48 \pm 0.06$ & $57.6 \pm 1.8$ \\
$20 / 30$ & $20.9 \pm 0.5$ & $650 \pm 24$ & $2.40 \pm 0.13$ & $60.5 \pm 0.4$ \\
$10 / 40$ & $21.6 \pm 1.0$ & $734 \pm 40$ & $2.76 \pm 0.19$ & $63.2 \pm 2.6$ \\
$0 / 50$ & $21.5 \pm 0.7$ & $660 \pm 23$ & $2.94 \pm 0.33$ & $65.0 \pm 6.5$ \\
\hline
\end{tabular}

2. the decreased crosslink density. Generally, the vulcanizates with relatively low crosslink density tend to give relatively high tear strength due to the greater energy dissipation through the higher molecular motion [43].

Fig. 7 illustrates heat build-up (HBU) and dynamic set of the vulcanizates. With increasing $\mathrm{SiO}_{2}$ fraction, there are undesirable increases in both HBU and dynamic set, demonstrating a rise in viscous response (or a reduction in elastic contribution). Such augmented viscous response is caused by a combination of the reduced crosslink density and the increase in the total contacting filler surface area, facilitating the greater slippage of the rubber molecules on the filler surface. This leads to the increased energy dissipation during the cyclic deformation and, thus, the rise in HBU [44].

Fig. 8 demonstrates fatigue resistance of the rubber vulcanizates, represented in terms of the number of kilocycles required to cause $2 \mathrm{~mm}$. crack length. Clearly, the fatigue resistance tends to increase continuously with increasing $\mathrm{SiO}_{2}$ fraction. The explanation is given to the improvement in rubber-filler interaction in association with the reduced crosslink density, facilitating the energy dissipation at the crack tip during the cyclic operation $[45,46]$.

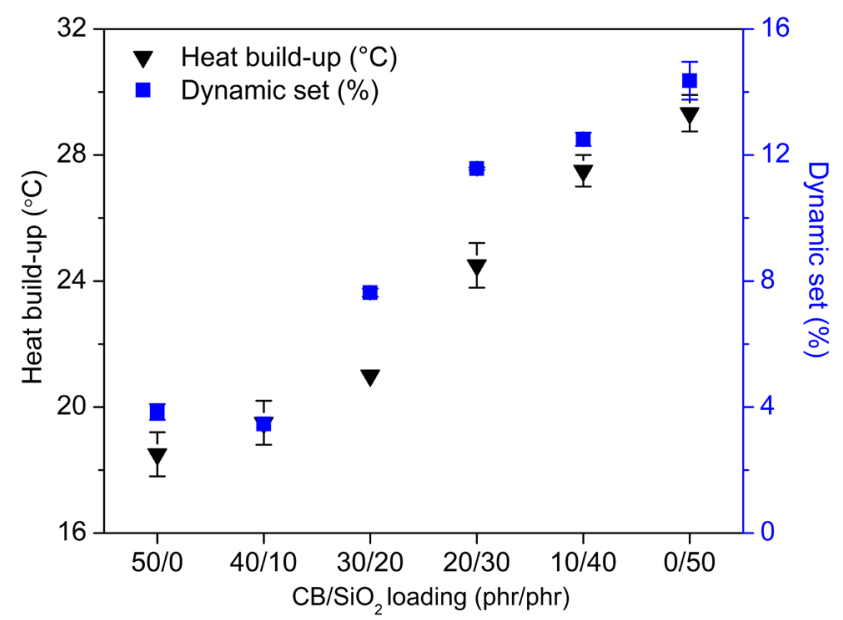

Fig. 7 Heat build-up (HBU) and dynamic set of the vulcanizates filled with various $\mathrm{CB} / \mathrm{SiO}_{2}$ hybrid loadings

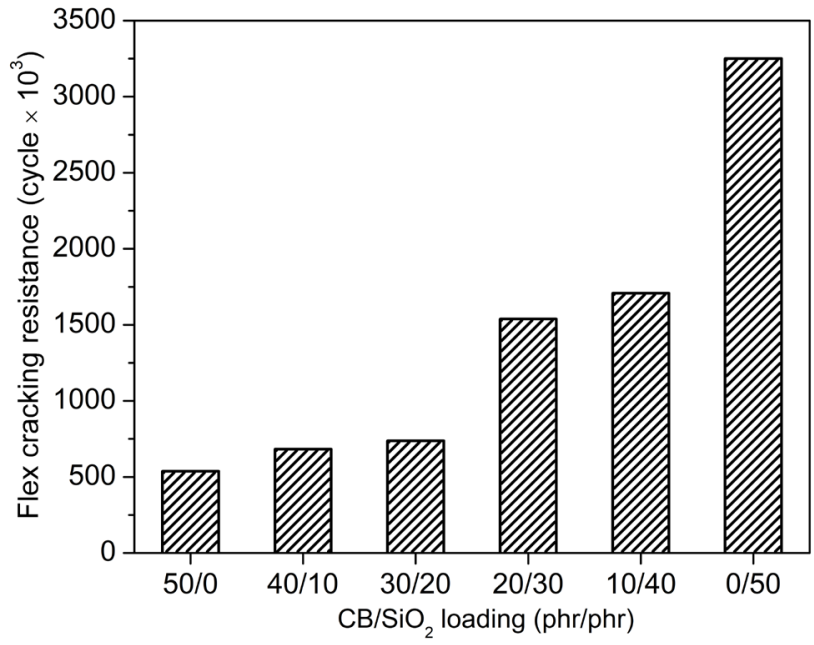

Fig. 8 Fatigue resistance of the vulcanizates filled with various $\mathrm{CB} / \mathrm{SiO}_{2}$ hybrid loadings

From the overall results, it is possible to summarize the effect of hybrid filler ratio on tire sidewall performance as illustrated in Fig. 9 in which the properties of the CB-filled vulcanizate were employed as references for normalization. Clearly, the $\mathrm{SiO}_{2}$-filled system (0/50) has higher strengths and fatigue resistance than the CB-filled system (50/0). Meanwhile, the use of sole $\mathrm{SiO}_{2}$ in the tire sidewall compound might lead to a significant increase in heat build-up, which is undesirable for tire sidewall. A proper selection of $\mathrm{CB} / \mathrm{SiO}_{2}$ ratio to achieve a good balance of the tire sidewall performance is therefore recommended.

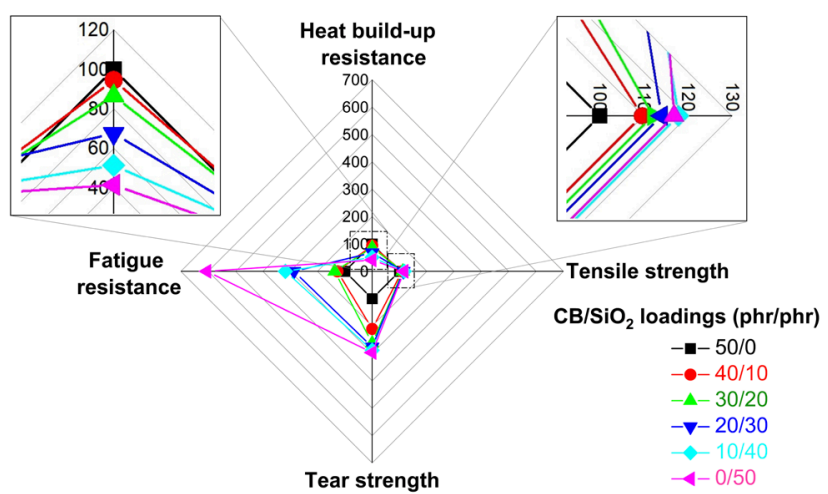

Fig. 9 Normalized graph of tire sidewall performance at various $\mathrm{CB} / \mathrm{SiO}_{2}$ hybrid loadings 


\section{Conclusions}

The tire sidewall compounds reinforced with a hybrid filler system of carbon black (CB) and precipitated silica $\left(\mathrm{SiO}_{2}\right)$ were prepared by varying the $\mathrm{SiO}_{2}$ fraction, and their properties were investigated. Results demonstrate the increases in hardness, modulus, tensile strength, tear strength as well as fatigue resistance with increasing $\mathrm{SiO}_{2}$ fraction, at the expense of the hysteretic behavior (i.e., impaired heat build-up and dynamic set). The overall results provide the advantages and disadvantages of using $\mathrm{CB} / \mathrm{SiO}_{2}$ hybrid filler over the sole use of $\mathrm{CB}$ in the production of tire sidewall compound. With a proper selection of $\mathrm{CB} / \mathrm{SiO}_{2}$ ratio, optimal performance of tire sidewall can be achieved. Practically, the hardness of the tire sidewall should be maintained constant

\section{References}

[1] Wang, Y. X., Wu, Y. P., Li, W. J., Zhang, L. Q. "Influence of filler type on wet skid resistance of SSBR/BR composites: Effects from roughness and micro-hardness of rubber surface", Applied Surface Science, 257(6), pp. 2058-2065, 2011.

https://doi.org/10.1016/j.apsusc.2010.08.129

[2] Ten Brinke, J. W., Debnath, S. C., Reuvekamp, L. A. E. M., Noordermeer, J. W. M. "Mechanistic aspects of the role of coupling agents in silica-rubber composites", Composites Science and Technology, 63(8), pp. 1165-1174, 2003.

https://doi.org/10.1016/S0266-3538(03)00077-0

[3] Saeed, F., Ansarifar, A., Ellis, R. J., Haile $\square$ Meskel, Y., Irfan, M. S. "Two advanced styrene $\square$ butadiene/polybutadiene rubber blends filled with a silanized silica nanofiller for potential use in passenger car tire tread compound", Journal of Applied Polymer Science, 123(3), pp. 1518-1529, 2012.

https://doi.org/10.1002/app.34221

[4] Liu, X., Zhao, S., Zhang, X., Li, X., Bai, Y. "Preparation, structure, and properties of solution-polymerized styrene-butadiene rubber with functionalized end-groups and its silica-filled composites", Polymer, 55(8), pp. 1964-1976, 2014.

https://doi.org/10.1016/j.polymer.2014.02.067

[5] Ko, J. Y., Prakashan, K., Kim, J. K. "New silane coupling agents for silica tire tread compounds", Journal of Elastomers \& Plastics, 44(6), pp. 549-562, 2012.

https://doi.org/10.1177/0095244312439489

[6] Thaptong, P., Sae $\square$ Oui, P., Sirisinha, C. "Effects of silanization temperature and silica type on properties of silica $\square$ filled solution styrene butadiene rubber (SSBR) for passenger car tire tread compounds", Journal of Applied Polymer Science, 133(17), Article number: 43342, 2016.

https://doi.org/10.1002/app.43342

[7] Reuvekamp, L. A. E. M., ten Brinke, J. W., van Swaaij, P. J., Noordermeer, J. W. M. "Effects Of Time and Temperature on the Reaction of Tespt Silane Coupling Agent During Mixing with Silica Filler and Tire Rubber", Rubber Chemistry and Technology, 75(2), pp. 187-198, 2002.

https://doi.org/10.5254/1.3544972 after the formulation adjustment. Substantial replacement of medium reinforcing CB (N660) by a superior reinforcing $\mathrm{SiO}_{2}$ (Hisil 255) therefore permits the reduction of total filler loading in the compound formulation which could reduce the undesirable increases in heat build-up and dynamic set of the $\mathrm{SiO}_{2}$-rich systems.

\section{Acknowledgments}

This work was financially supported by the Thailand Graduate Institute of Science and Technology (TGIST SCA-CO-2561-7108TH) funded under the National Science and Technology Development Agency (NSTDA), Thailand. The authors thank the Rubber Technology Research Centre (RTEC), Faculty of Science, Mahidol University for supporting research facilities.

[8] Kim, W., Yu, E., Ryu, G., Kim, D., Ryu, C., Seo, Y., Kim, W. "Silica dispersion and properties of silica filled ESBR/BR/NR ternary blend composites by applying wet masterbatch technology", Polymer Testing, 84, Article number: 106350, 2020. https://doi.org/10.1016/j.polymertesting.2020.106350

[9] Semsey, Á. "Experimental and Numerical Investigation Into NonRolling Tyre", Periodica Polytechnica Transportation Engineering, 22(1), pp. 15-23, 1994. [online] Available at: https://pp.bme.hu/tr/ article/view/6620 [Accessed: 21 February 2021]

[10] Rodgers, B., Waddell, W. "The Science of Rubber Compounding", In: Mark, J. E., Burak, E., Eirich, F. R. (eds.) The Science and Technology of Rubber, Academic Press, Cambridge, MA, USA, 2005, pp. 401-454.

https://doi.org/10.1016/B978-012464786-2/50012-2

[11] Luginsland, H. D., Niedermeier, W. "New reinforcing materials for rising tire performance demands", Rubber World, 228(6), pp. 34-45, 2003. [online] Available at: http://rubber.docegon.com/ papers/1266-NEW-REINFORCING-MATERIALS-FOR-RISING-TIRE-PERFORMANCE-DEMANDS [Accessed: 28 April 2003]

[12] Atashi, H., Shiva, M. "Formulation for Passenger Tread Tire Compound Based on Styrene Butadiene Rubber/cis-Butadiene Rubber/Natural Rubber Blend and Semi-Dispersible Silica/ Carbon Black Filler System", Asian Journal of Chemistry, 22(10), pp. 7519-7530, 2010. [online] Available at: http://www. asianjournalofchemistry.co.in/User/ViewFreeArticle.aspx?ArticleID=22_10_10 [Accessed: 01 November 2010]

[13] Sattayanurak, S., Sahakaro, K., Kaewsakul, W., Dierkes, W. K., Reuvekamp, L. A., Blume, A., Noordermeer, J. W. "Synergistic effect by high specific surface area carbon black as secondary filler in silica reinforced natural rubber tire tread compounds", Polymer Testing, 81, Article number: 106173, 2020. https://doi.org/10.1016/j.polymertesting.2019.106173

[14] Thottathil, S., Thomas, S., Kalarikkal, N., Rouxel, D. (eds.) "Advanced Polymeric Materials for Sustainability and Innovations", Apple Academic Press, Bota Raton, FL, USA, 2018. https://doi.org/10.1201/b22326 
[15] Colombo, L., Busetti, S., Di Pasquale, A., Miani, B. "A new high cis polybutadiene for improved tyre performance", Kautschuk und Gummi, Kunststoffe, 46(6), pp. 458-461, 1993.

[16] Bijarimi, M., Zulkafli, H., Beg, M. D. H. "Mechanical Properties of Industrial Tyre Rubber Compounds", Journal of Applied Sciences, 10(13), pp. 1345-1348, 2010.

https://doi.org/10.3923/jas.2010.1345.1348

[17] Brindha, M., Mahapatra, D. "Effect of reinforcing fillers on the DeMattia cut growth and dynamic properties of a model sidewall compound", Rubber World, 241(6), pp. 34-40, 2010. [online] Available at: http://digitaleditions.walsworthprintgroup.com/publication/?i=33853 [Accessed: 01 March 2010]

[18] Kim, H., Hamed, G. "On the Reason that Passenger Tire Sidewalls are Based on Blends of Natural Rubber and cis-Polybutadiene", Rubber Chemistry and Technology, 73(4), pp. 743-752, 2000. https://doi.org/10.5254/1.3547618

[19] Wang, H., Zhang, X., Nie, H., Wang, R., He, A. "Multi-block copolymer as reactive multifunctional compatibilizer for NR/BR blends with desired network structures and dynamical properties: Compatibility, co-vulcanization and filler dispersion", Composites Part A: Applied Science and Manufacturing, 116, pp. 197-205, 2019. https://doi.org/10.1016/j.compositesa.2018.11.001

[20] Ghosh, P., Stocek, R., Gehde, M., Mukhopadhyay, R., Krishnakumar, R. "Investigation of fatigue crack growth characteristics of NR/BR blend based tyre tread compounds", International Journal of Fracture, 188(1), pp. 9-21, 2014. https://doi.org/10.1007/s10704-014-9941-9

[21] Jang, J., Inoue, Y., Iwasa, M., Yoshida, H. "Nanoparticle distribution in NR/BR blend", Journal of Thermal Analysis and Calorimetry, 123(3), pp. 1841-1846, 2016. https://doi.org/10.1007/s10973-015-5119-6

[22] Wolff, S., Wang, M. J., Tan, E. H. "Filler-Elastomer Interactions. Part VII. Study on Bound Rubber", Rubber Chemistry and Technology, 66(2), pp. 163-177, 1993. https://doi.org/10.5254/1.3538304

[23] Wolff, S. "Chemical Aspects of Rubber Reinforcement by Fillers", Rubber Chemistry and Technology, 69(3), pp. 325-346, 1996. https://doi.org/10.5254/1.3538376

[24] Pliskin, I., Tokita, N. "Bound rubber in elastomers: Analysis of elastomer-filler interaction and its effect on viscosity and modulus of composite systems", Journal of Applied Polymer Science, 16(2), pp. 473-492, 1972.

https://doi.org/10.1002/app.1972.070160217

[25] Choi, S. S. "Effect of bound rubber on characteristics of highly filled styrene-butadiene rubber compounds with different types of carbon black", Journal of Applied Polymer Science, 93(3), pp. 1001-1006, 2004. https://doi.org/10.1002/app.20567

[26] Sridhar, V., Gupta, B. R., Tripathy, D. K. "Bound rubber in chlorobutyl compounds: Influence of filler type and storage time", Journal of Applied Polymer Science, 102(1), pp. 715-720, 2006. https://doi.org/10.1002/app.23031

[27] Thaptong, P., Sae-oui, P., Sirisinha, C. "Influences of styrene butadiene rubber and silica types on performance of passenger car radial tire tread", Rubber Chemistry and Technology, 90(4), pp. 699-713, 2017.

https://doi.org/10.5254/rct.17.83724
[28] International Organization for Standardization "ISO 289-1:2015 Rubber, unvulcanized - Determinations using a shearing-disc viscometer - Part 1: Determination of Mooney viscosity", International Organization for Standardization, Geneva, Switzerland, 2015.

[29] International Organization for Standardization "ISO 65023:2018 Rubber - Measurement of vulcanization characteristics using curemeters - Part 3: Rotorless curemeter", International Organization for Standardization, Geneva, Switzerland, 2018.

[30] International Organization for Standardization "ISO 48-4:2018 Rubber, vulcanized or thermoplastic - Determination of hardness — Part 4: Indentation hardness by durometer method (Shore hardness)", International Organization for Standardization, Geneva, Switzerland, 2018.

[31] International Organization for Standardization "ISO 37:2017(en) Rubber, vulcanized or thermoplastic - Determination of tensile stress-strain properties", International Organization for Standardization, Geneva, Switzerland, 2017.

[32] International Organization for Standardization "ISO 34-1:2010 Rubber, vulcanized or thermoplastic - Determination of tear strength - Part 1: Trouser, angle and crescent test pieces", International Organization for Standardization, Geneva, Switzerland, 2018.

[33] International Organization for Standardization "ISO 4666-3:2010 Rubber, vulcanized - Determination of temperature rise and resistance to fatigue in flexometer testing - Part 3: Compression flexometer (constant-strain type)", International Organization for Standardization, Geneva, Switzerland, 2010.

[34] International Organization for Standardization "ISO 132:2017 Rubber, vulcanized or thermoplastic - Determination of flex cracking and crack growth (De Mattia)", International Organization for Standardization, Geneva, Switzerland, 2017.

[35] Ahmed, K., Nizami, S. S., Raza, N. Z., Habib, F. "The effect of silica on the properties of marble sludge filled hybrid natural rubber composites", Journal of King Saud University-Science, 25(4), pp. 331-339, 2013.

https://doi.org/10.1016/j.jksus.2013.02.004

[36] Ansarifar, A., Nijhawan, R. "Effects of Silane on Properties of Silica Filled Natural Rubber Compounds", 3(3), pp. 169-184, 2000. [online] Available at: https://www.researchgate.net/profile/A_Ansarifar/ publication/258807062_Effects_of_silane_on_properties_of_silica_filled_natural_rubber_compounds/links $/ 5 \mathrm{~d} 429 \mathrm{e} 77 \mathrm{a} 6 \mathrm{fd}$ cc370a715419/Effects-of-silane-on-properties-of-silica-fillednatural-rubber-compounds.pdf [Accessed: 29 September 2000]

[37] Klüppel, M., Schuster, R. H., Heinrich, G. "Structure and Properties of Reinforcing Fractal Filler Networks in Elastomers", Rubber Chemistry and Technology, 70(2), pp. 243-255, 1997. https://doi.org/10.5254/1.3538429

[38] Heinrich, G., Klüppel, M., Vilgis, T. A. "Reinforcement of elastomers", Current Opinion in Solid State and Materials Science, 6(3), pp. 195-203, 2002. https://doi.org/10.1016/S1359-0286(02)00030-X

[39] Sahakaro, K. "3 - Mechanism of reinforcement using nanofillers in rubber nanocomposites", In: Thomas, S., Maria, H. J. (eds.) Progress in Rubber Nanocomposites, Woodhead Publishing, Cambridge, UK, 2017, pp. 81-113.

https://doi.org/10.1016/B978-0-08-100409-8.00003-6 
[40] Choi, S. S., Choi, S. J. "Influence of Silane Coupling Agent Content on Crosslink Type and Density of Silica-Filled Natural Rubber Vulcanizates", Bulletin of the Korean Chemical Society, 27(9), pp. 1473-1476, 2006

https://doi.org/10.5012/bkcs.2006.27.9.1473

[41] Choi, S. S., Kim, I. S., Woo, C. S. "Influence of TESPT content on crosslink types and rheological behaviors of natural rubber compounds reinforced with silica", Journal of Applied Polymer Science, 106(4), pp. 2753-2758, 2007.

https://doi.org/10.1002/app.25744

[42] Briscoe, B. J., Sinha, S. K. "Hardness and Normal Indentation of Polymers", In: Swallowe, G. M. (ed.) Mechanical Properties and Testing of Polymers : an A-Z reference, Springer, Dordrecht, Netherlands, 1999, pp. 113-121.

https://doi.org/10.1007/978-94-015-9231-4
[43] Zhao, J., Ghebremeskel, G. N. "A Review of Some of the Factors Affecting Fracture and Fatigue in SBR and BR Vulcanizates", Rubber Chemistry and Technology, 74(3), pp. 409-427, 2001. https://doi.org/10.5254/1.3547645

[44] Donnet, J. B., Bansal, R. C., Wang, M. J. "Carbon Black: Science and Technology", CRC Press, Boca Raton, FL, USA, 1993. https://doi.org/10.1201/9781315138763

[45] Persson, B., Albohr, O., Heinrich, G., Ueba, H. "Crack propagation in rubber-like materials", Journal of Physics: Condensed Matter, 17(44), pp. R1071-R1142, 2005.

https://doi.org/10.1088/0953-8984/17/44/R01

[46] Dong, B., Liu, C., Wu, Y. P. "Fracture and fatigue of silica/carbon black/natural rubber composites", Polymer Testing, 38, pp. 40-45, 2014.

https://doi.org/10.1016/j.polymertesting.2014.06.004 